(C) Copyright 2019: Editum. Servicio de Publicaciones de la Universidad de Murcia. Murcia (Spain) ISSN print edition: 0212-9728. ISSN on line edition (http://revistas.um.es/analesps): 1695-2294. On line edition License Creative Commons 4.0: BY-NC-ND

\title{
Quality of Life in Breast Cancer Patients: The Moderator Role of Family Stress
}

\author{
M. Graça Pereira ${ }^{1, *}$, Ana Cristina Paredes ${ }^{1,2}$, Rui $\mathrm{Nabiço}^{3}$, Catarina Ribeiro ${ }^{1}$, and Gabriela Ferreira ${ }^{1}$ \\ 1 University of Minho, School of Psychology, Braga, Portugal \\ 2 Life and Health Sciences Research Institute (ICVS), School of Medicine, University of Minho, Braga, Portugal and \\ CVS/3B's - PT Government Associate Laboratory, Bragal Guimarães, Portugal \\ 3 Hospital de Braga, Braga, Portugal
}

\begin{abstract}
Título: Calidad de Vida en Pacientes con Cáncer de Mama: El Papel Moderador del Estrés Familiar.

Resumen: En pacientes con cáncer de mama, la calidad de vida se ha asociado con la respuesta al tratamiento y la supervivencia global. Cien mujeres sometidas a tratamiento de quimioterapia para el cáncer de mama completaron cuestionarios incluyendo información demográfica y clínica, Cuestionario de Calidad de Vida EORTC, Escalas de Ansiedad y Depresión Hospitalaria, Escala de Imagen Corporal, Indice de Relaciones Familiares y el Test de Orientación Vital. Los resultados mostraron que un mayor optimismo y una mejor imagen corporal se asociaron con una mejor calidad de vida. La morbilidad psicológica predijo significativamente la calidad de vida física y emocional, pero la recurrencia sólo predijo la calidad de vida física. El estrés familiar fue un moderador en la relación entre la morbilidad psicológica y la calidad de vida emocional, mostrando la necesidad de detectar e intervenir en el estrés familiar en pacientes con cáncer de mama. Los resultados pueden ayudar en el diseño de intervenciones para las mujeres con cáncer de mama con el fin de promover la calidad de vida.
\end{abstract}

Palabras clave: Cáncer de mama; optimismo; imagen corporal; estrés familiar; calidad de vida.

\section{Introduction}

Breast cancer is the most common type of cancer in women in all European countries and the first cause of death in women (Ferlay et al., 2013). Chemotherapy is a form of treatment widely used to treat breast cancer and prevent cancer growth and dissemination. It is composed of a mixture of different chemicals in different concentrations depending on the type and stage of the cancer being treated; with side effects diverging accordingly, ranging from changes in humor, hair weakening or loss and diminished resistance to infections and inflammation, to pain, nausea and vomiting (Breast Cancer Treatment Option Overview, 2018; Ogden, 2004). During the active treatment phase, it is important to consider the quality of life (QoL) since chemotherapy and other treatments, such as radiation and breast cancer surgery, are responsible for several side effects that have a strong impact on women's wellbeing and body image (Browall et al., 2008; Collins et al., 2010). Literature shows that patients under treatment for breast cancer not only report worse physical function and QoL than the general population (Penttinen et al., 2010), but also lower physical and global QoL, when

* Correspondence address [Dirección para correspondencia]

M. Graça Pereira, Associate Professor with Aggregation, University of Minho, School of Psychology, Campus de Gualtar, 4710-057. Braga (Portugal). E-mail: gracep@psi.uminho.pt

(Article received: 12-09-2017; revised: 05-02-2018; accepted: 01-11-2018)
Abstract: In breast cancer patients, quality of life has been associated with treatment response and overall survival. One hundred women undergoing chemotherapy treatment for breast cancer completed questionnaires including demographic and clinical information, the EORTC - Quality of Life Questionnaire, Hospital Anxiety and Depression Scales, Body Image Scale, Index of Family Relations and the Life Orientation Test. The results showed that higher optimism and better body image were associated with improved quality of life. Distress significantly predicted physical and emotional quality of life, but recurrence only predicted physical quality of life. Family stress was a moderator in the relationship between psychological distress and emotional quality of life, showing the need to screen and intervene on family stress in patients with breast cancer. The results may help in designing interventions for women with breast cancer in order to promote quality of life.

Keywords: Breast cancer; optimism; body image; family stress; quality of life.

compared to recently diagnosed patients or survivors (Silva, Bettencourt, Moreira, \& Canavarro, 2011).

Optimism can be conceptualized through two theoretical perspectives: dispositional optimism and explanatory style. Dispositional optimism is a personality trait that describes a relatively stable general disposition to expect positive outcomes in different situations (Carver, Scheier, \& Segerstrom, 2010; Scheier \& Carver, 1985). The explanatory style (Seligman, 1992), in turn, comprises the assumption that expectations regarding the future result from the interpretation of the causes of past negative events. Thus, individuals with an optimistic explanatory style would interpret the negative events as having a specific context, temporary, and external (no guilt feelings) causes.

Studies are controversial regarding the stability of optimism as a personality trait. It has been suggested that optimism remains relatively stable over time, mainly if there were no significant life transitions (Carver et al., 2010). A study conducted with women with breast cancer found that the levels of dispositional optimism did not change regardless of the reception of bad news, which lead the authors to conclude that optimism was a personality trait that remains stable not only over time but also regardless of the situation (Schou, Ekeberg, Sandvik, Hjermstad, \& Ruland, 2005). On the other hand, other authors suggested that optimism might change over short periods of time and, therefore, has a state and not a trait property (Shifren, 1996; Shifren \& Hooker, 1995). 
Optimism has been extensively researched in recent years, and has consistently been shown to influence patients' QoL, in chronic illnesss (Stanton, Revenson, \& Tennen, 2007; Vilhena et al., 2014). Optimism has also been linked to better mental and physical health, in a variety of cancer locations (Allison, Guichard, \& Gilain, 2000; Zenger, Brix, Borowski, Stolzenburg, \& Hinz, 2009), including breast cancer (Colby \& Shifren, 2013; Scheier \& Carver, 1992; Schou et al., 2005), as well as a predictor of health outcomes, long-term QoL, and physical well-being (Carver et al., 2005; Carver, Smith, Petronis, \& Antoni, 2006; Petersen et al., 2008; Rasmussen, Scheier, \& Greenhouse, 2009). The recognized positive impact of optimism on health and its association with decreased psychological distress is important in order to understand the role of optimism on patient's QoL (Carver et al., 2005; Carver et al., 2006; Colby \& Shifren, 2013).

Family stress has also been related to cancer adjustment. A cancer diagnosis is a very stressful event that affects both the patient and the family. Family functioning patterns, in particular, have been found to influence patients' distress during and after treatment (Edwards \& Clarke, 2004; Kissane et al., 1996), due to the changes in family roles required to cope with cancer, as well as on patients' mental and physical QoL (Northouse et al., 2002). However, studies regarding the role of family stress in breast cancer women during treatment (Moreira, Fernandes, Gomes, Silva, \& Santos, 2013) are scarce and, from a heuristic point of view, it is important to understand how family stress may impact patients at risk of poor adjustment, with direct impact on QoL. Therefore, in the present study, the moderating role of family stress was analyzed.

Women with breast cancer often report body image issues related to treatment side effects (Collins et al., 2010; Fobair et al., 2006). Chemotherapy induced alopecia is described as a troublesome event that impacts body image causing distress, which may negatively impact QoL (Lemieux, Maunsell, \& Provencher, 2008). Several studies have revealed that problems with body image were related to lower QoL and more psychological distress (Al-Ghazal, Fallowfield, \& Blamey, 1999; Avis, Crawford, \& Manuel, 2005; Helms, O’Hea, \& Corso, 2008).

Psychological distress is common among cancer patients, during the active treatment phase, with a reported prevalence of $37.5 \%$ for moderate depression and $15.6 \%$ for moderate or severe anxiety, during chemotherapy (Reece, Chan, Herbert, Gralow, \& Fann, 2013). Adjuvant treatments are associated with increased anxiety and depression (Browall et al., 2008) that in turn have been related to several QoL dimensions due to dysphoria, stress, less interpersonal relationships, and impaired performance (Penttinen et al., 2010; Reich, Lesur, \& Perdrizet-Chevallier, 2007; So et al., 2010). In fact, anxiety and depression have been shown to be independently related to QoL in breast cancer patients, especially regarding the emotional, physical and functional dimensions (Ho, So, Leung, Lai, \& Chan, 2013).
Given the multiplicity of dimensions related to QoL assessment, this study focused on QoL dimensions of emotional and physical functioning. Emotional (or psychological) QoL is conceptualized as the individuals' perception of affective and cognitive wellbeing, while physical QoL refers to the perception of one's physical condition that has been shown to significantly predict survival (Braun, Gupta, Grutsch, \& Staren, 2011; Gupta, Granick, Grutsch, \& Lis, 2006; Seidl \& Zannon, 2004).

Models of psychosocial adaptation to chronic illness and disability (Livneh \& Antonak, 2005; Northouse, Kershaw, Mood, \& Schafenacker, 2005) emphasize the process and strategies involved in adapting/overcoming the impact of chronic disease, such as cancer, on QoL. Based on these theoretical frameworks, dispositional optimism, body image and family stress were analyzed, in this study, as psychological attributes that may influence adaptation to chronic illness, with an impact on psychosocial outcomes, such as QoL. Therefore, the aims of this study were: 1) to analyze the relationship between psychological variables such as distress, family stress, body image, dispositional optimism and QoL; and 2) to find the clinical and psychological variables that contributed to physical and emotional QoL; 3) to analyze whether family stress moderated the relationship between patients' psychological distress and QoL, during breast cancer treatment.

\section{Method}

\section{Participants}

This study used a cross-sectional design. One hundred women participated in the study. The inclusion criteria were: a) age over 18 years old; b) diagnosis of breast cancer; and c) undergoing chemotherapy treatment at the moment of the evaluation. Information on demographic and clinical variables was collected through medical records, including duration of diagnosis and cancer recurrence. From the initial sample, $5 \%$ refused to participate in the study due to time constraints but they did not differ on sociodemographic and clinical variables from participants.

\section{Instruments}

EORTC QLQ-C30 (Aaronson et al., 1993; Portuguese version of Pais-Ribeiro, Pinto, \& Santos, 2008). The QLQC30 assesses 9 cancer related QoL dimensions using 24 items grouped into functional (physical, role, cognitive, emotional and social), global health/QoL and symptom subscales (fatigue, pain, and nausea/vomiting). The other 6 items assess symptoms of dyspnea, appetite loss, sleep disturbance, constipation and diarrhea. Higher scores on functional and global health/QoL indicate a higher level of functioning and better QoL. Higher scores on symptom subscales indicate more severe symptoms. For the purpose of this study, only the physical (5 items) and emotional (4 items) subscales were 
included in the analysis with Cronbach's alphas in this sample of .71 and .87 for each dimension, respectively.

Hospital Anxiety and Depression Scales - HADS (Zigmond \& Snaith, 1983; Portuguese version of Pais-Ribeiro et al., 2007). This scale assesses global psychological distress with 14 items answered on a 4-point Likert scale (0-3), according to symptom frequency during the previous week. Separate scores can also be computed for anxiety and depression subscales, with 7 items evaluating depression and 7 items assessing anxiety. Higher scores indicate higher anxiety/depression or psychological distress. In the present study, Cronbach's alpha was .86 for the global scale.

Body Image Scale - BIS (Hopwood, Fletcher, Lee, \& AlGhazal, 2001; Portuguese version by Moreira, Silva, Marques, \& Canavarro, 2010). BIS is a 10 item self-report measure that evaluates the cancer patient's body image using a 3-point Likert scale with scores ranging from 0 to 30. Higher scores indicate worst body image. Cronbach's alpha for this sample was 94 .

Life Orientation Test-Revised (LOT-R) (Scheier, Carver, \& Bridges, 1994; Portuguese version by Laranjeira, 2008). The LOT-R is a 10 -item measure, with 3 items that assess an optimistic view of the future, and 3 items reflecting negative expectations. The 4 remaining items act as distractions and are not used in the analysis (e.g.: "I enjoy my friends a lot"). The items are answered according to a 5 -point Likert scale ranging from 0 (strongly disagree) to 4 (strongly agree). For this study, optimism was considered a unidimensional construct and the scores were calculated using the optimistic and the reversed pessimistic items. Therefore, higher scores indicate higher dispositional optimism. In this sample Cronbach's alpha was .72.

Index of Family Relations- IFR (Hudson, 1992; Portuguese version by Pereira \& Roncon, 2010). The IFR is a 25 -item measure of family stress that assesses the severity of problems in the family. The IFR produces a 0-100 score with higher scores indicating more severe problems. In this study, Cronbach's alpha was .89 for the IFR.

\section{Procedure}

Data was collected in an oncology unit of a central hospital in the North of Portugal using a consecutive sample of women undergoing chemotherapy treatment for breast cancer. Patients were approached by a research team member and invited to participate in the study, the day of the chemotherapy session. Participation was voluntary. The study was approved by the hospital's Ethical Committee and all participants were knowledgeable of the purposes of the study and signed an informed consent.

\section{Statistical analysis}

Pearson correlation was used to analyze the association between continuous variables, and the point-biserial correlation was used regarding the dichotomous variables. Clinical variables significantly associated with QoL were introduced in the regression model to determine their association with physical and emotional QoL. For this purpose, two separate hierarchical regression models (method enter) were computed, with clinical variables introduced in step 1 and psychological variables in step 2. Duration of diagnosis was categorized in two groups: over six months (44\%) and less than six months $(56 \%)$. The moderation analysis was performed using the Baron and Kenny's method (1986).

The statistical analyses were performed using the IBM SPSS Statistics 24 with the level of significance set at $p<.05$.

\section{Results}

\section{Sociodemographic and Clinical Characteristics}

The mean age of women was $52.45(S D=11.93)$. From the total sample, $45 \%$ completed primary school education, $27 \%$ reported having 9 years of education and $28 \%$ high school education or more. Most participants were married or in a long-term relationship (76\%), 9\% were single, $6 \%$ divorced, and $5 \%$ widowed.

Approximately half the women had been diagnosed for less than 6 months $(56 \%)$ and $29 \%$ had recurrent breast cancer. Seventy-seven per cent of women had breast cancer surgery, either a mastectomy $(63.5 \%)$ or breast conserving surgery $(36.5 \%)$.

\section{Relationship between Clinical and Psychological Variables and QoL}

The results showed that duration of diagnosis $(r=-.365$, $p<.001)$ and cancer recurrence $(r=-.394, p<.001)$ were negatively associated with physical QoL. However, there were no differences according to type of surgery (mastectomy vs breast conserving) on body image $(t(71)=.967, p=$ $.337)$, physical QoL $(t(71)=-1.919, p=.059)$, and emotional QoL $(t(72)=-.499, p=.620)$.

Physical QoL was negatively associated with psychological distress $(r=-.412, p<.001)$ and body image $(r=-.392, p$ $<.001)$. Emotional QoL was negatively associated with psychological distress $(r=-.676, p<.001)$, body image $(r=-$ $.397, p<.001)$, and family stress $(r=-.339, p=.001)$. Therefore, women with lower physical QoL levels reported more psychological symptoms and worst body image, and women with lower emotional QoL also showed more family stress.

Dispositional optimism was positively related to physical $(r=.205, p=.042)$ and emotional $(r=.293, p=.003)$ QoL. Women with more psychological distress also reported worst body image $(r=.597, p<.001)$ and more family stress $(r=$ $.387, p<.001)($ Table 1$)$. 
Table 1. Correlation between Clinical and Psychological Variables in QoL $(N=100)$.

\begin{tabular}{|c|c|c|c|c|c|c|c|}
\hline Measure & 1 & 2 & 3 & 4 & 5 & 6 & 7 \\
\hline 1.Diagnosis Duration & ----- & & & & & & \\
\hline 2. Recurrence & $721 * * *$ & ----- & & & & & \\
\hline 3. Distress & $.293^{* *}$ & $.203^{*}$ & --- & & & & \\
\hline 4. Family Relations & -.072 & -.116 . & $387^{*}$ & ----- & & & \\
\hline 5. Body Image & $352^{* * *}$ & $.216^{*}$. & $597 *$ & $289 *$ & ----- & & \\
\hline 6. Optimism & -.147 & -.053 & $554^{\star}$ & $295 *$ & $508^{3}$ & ---- & \\
\hline 7.Physical QoL & $365^{* *}$ & 394**: & $412^{*}$ & .136 & 392 & .205 & ----- \\
\hline 8. Emotional QoL & -.128 & -.119 & $676^{*}$ & $339 *$ & .397 & 293 & $.301^{2}$ \\
\hline
\end{tabular}

\section{Contribution of Clinical and Psychological Variables to Physical and Emotional QoL}

Physical QoL was associated with cancer recurrence and psychological distress, and the model explained 30\% of the variance. Women with recurrent breast cancer and higher psychological distress reported lower physical QoL. Psychological distress was the only variable associated with emotional QoL, with the model explaining $48 \%$ of the variance (Table 2).

Table 2. Hierarchical Regression Models Regarding Physical and Emotional QoL $(N=100)$.

\begin{tabular}{|c|c|c|c|c|c|c|c|c|}
\hline \multirow[b]{3}{*}{ Variables } & \multicolumn{8}{|c|}{ QoL (QLQ) } \\
\hline & \multicolumn{4}{|c|}{ Physical QoL } & \multicolumn{4}{|c|}{ Emotional QoL } \\
\hline & $\Delta R^{2}$ & $\beta$ & $t$ & $p$ & $\Delta R^{2}$ & $\beta$ & $t$ & $p$ \\
\hline Step 1 & .169 & & & & .018 & & & \\
\hline - Duration of Diagnosis & & -.169 & -1.258 & -211 & & -.087 & -.601 & .549 \\
\hline - Cancer Recurrence & & -.273 & -2.038 & .044 & & -.056 & -.388 & .699 \\
\hline & & & & $2^{2}: .1$ & & & $\mathrm{Ac}$ & -.002 \\
\hline Step 2 & .296 & & & & .482 & & & \\
\hline - Duration of Diagnosis & & -.029 & -.219 & .827 & & .120 & 1.053 & .295 \\
\hline - Cancer Recurrence & & -.292 & -2.297 & .024 & & -.070 & -.645 & .521 \\
\hline - Psychological Distress & & -.250 & -2.048 & .043 & & -.711 & -6.788 & .000 \\
\hline - Family Stress & & -.041 & -.413 & .681 & & -.091 & -1.289 & .279 \\
\hline - Body Image & & -.188 & -1.608 & .111 & & -.043 & -.425 & .672 \\
\hline - Optimism & & -.057 & -.521 & .603 & & -.136 & -1.451 & .150 \\
\hline & & & & $2^{2}: .2$ & & & & $: .448$ \\
\hline
\end{tabular}

\section{Moderation Analysis}

Since there were no differences on family stress according to the presence/absence of a partner $(U=768.00, p=$ $.78)$, the moderation analysis was performed for the entire sample. Results showed that family stress was a significant moderator in the relationship between psychological distress and emotional QoL but not in the relationship between psychological distress and physical QoL. When family stress was high $(t=-5.57, p<.001)$, there was a negative relationship between psychological distress and emotional QoL $(r=$ 6.76, $p<.001)$. Therefore, family stress seems to have a higher impact on emotional rather than physical QoL (Figure 1).

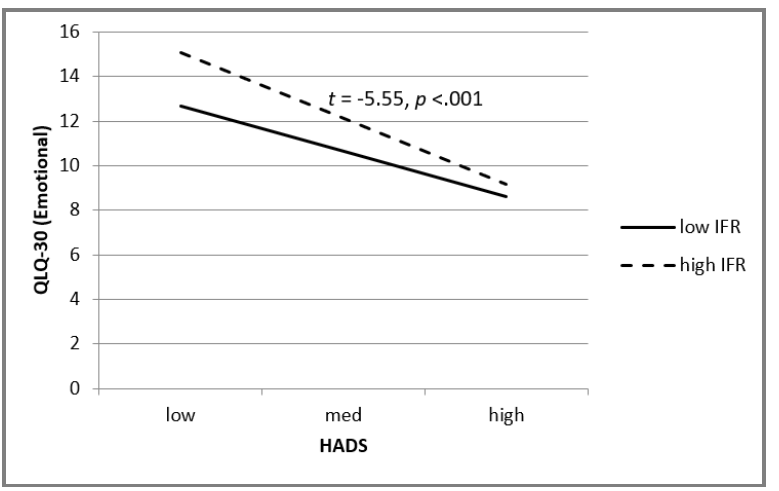

Figure 1. The moderator role of Family Stress in the relationship between Distress and QoL.

\section{Discussion and Conclusion}

This study aimed to analyze the relationship between clinical and psychological variables in breast cancer patients undergoing chemotherapy treatment; to determine the predictors of physical and emotional QoL; and to analyze the role of family stress as a moderator in the relationship between psychological distress and QoL. Results showed that lower QoL was related to less dispositional optimism, more psychological distress and dissatisfaction with body image. Higher psychological distress was associated with lower physical and emotional QoL and cancer recurrence was also associated with physical QoL. The relationship between psychological distress and emotional QoL was moderated by family stress.

The significant relationship between psychological distress, body image and QoL reinforces the importance of body image, showing that women with worse body image, in this study, also reported lower QoL and more psychological disturbances (Avis et al., 2005; Helms et al., 2008; Rosenberg et al., 2012). These results are probably due to physical changes related to cancer treatments that may create a discrepancy from the ideal-self, causing distress or adjustment disorders (White, 2000; White \& Hood, 2011).

The influence of psychological factors on QoL has been consistently reported in several studies that showed a general consensus in cancer research concerning the negative influence of psychological distress on both physical and emotional QoL. In fact, feelings of stress and fear add to the emo- 
tional burden of cancer (Holzner et al., 2001; Penttinen et al., 2010; So et al., 2010), and depression symptoms increase the perception of pain, side effects severity, and are associated with physical symptom intensity (Badger, Braden, Mishel, \& Longman, 2004; Reich et al., 2007), making depressed patients more likely to report impaired QoL (Ardebil, Bouzari, Shenas, Zeinalzadeh, \& Barat, 2011). In a study by Rabin, Heldt, Hirakata, and Fleck (2008), depressive symptoms predicted all QoL dimensions and the initial psychological distress was the most important predictor of long term QoL, underlying the importance of evaluating patients' psychological symptoms, especially considering the association of QoL with psychological distress and overall survival (Montazeri, 2008).

The results concerning dispositional optimism are in line with the studies showing an association between optimism, QoL and emotional well-being. In women with breast cancer, studies have found that higher optimism and lower pessimism were related to better health-related QoL (Petersen et al., 2008), less depression and anxiety, as well as lower psychological distress (Applebaum et al., 2013; Leung, Atherton, Kyle, Hubbard, \& McLaughlin, 2015), and better social and mental functioning (Colby \& Shifren, 2013). Considering the results of the contribution of dispositional optimism to QoL, the present study is in accordance with the results of Härtl et al. (2010) that reported no significant predictive value for optimism. One possible explanation may have to do with the confounding effect between optimism and psychological distress, with the latter being a more important variable on QoL when considered together (Härtl et al., 2010). Nonetheless, it is clear that further research is needed to clarify the relationship between optimism and QoL, in different stages of disease breast cancer.

Cancer recurrence was associated with physical QoL showing its importance as a major stressor that impacts the patients' physical well-being, as has been shown by the literature (Northouse et al., 2005). These results highlight the need to better understand the psychological aspects of cancer recurrence, in order to promote better adjustment and decrease psychological strain, during chemotherapy treatment.

Moderation analysis showed a significant impact of high family stress on emotional QoL. Several studies have focused on the association between family functioning and psychological distress, reporting a direct relationship between family functioning and psychological distress (Kissane et al., 1996), highlighting the influence of problematic communication patterns, repressed feelings and less problem solving

\section{References}

Aaronson, N., Ahmedzai, S., Bergman, B., Bullinger, M., Cull, A., Duez, N., ... Takeda, F. (1993). The European Organization for Research and Treatment of Cancer QLQ-C30: A Quality-of-Life Instrument for Use in International Clinical Trials in Oncology. JNCI Journal of the National Cancer Institute, 85(5), 365-376. doi:10.1093/jnci/85.5.365

Al-Ghazal, S., Fallowfield, L., \& Blamey, R. (1999). Does cosmetic outcome from treatment of primary breast cancer influence psychosocial mor- skills on patient's distress (Edwards \& Clarke, 2004). The impact of family stress on emotional QoL may be due to the role that family members have to play on managing emotions and shaping patients' experience and feelings about cancer (Thomas, Morris, \& Harman, 2002), which explains why family stress acted as a moderator. This result adds to the importance of a family-centered approach in cancer care (Edwards \& Clarke, 2004), not only for patients but the family as well, during chemotherapy treatment.

\section{Conclusion}

Given the role that psychological distress and QoL have on cancer treatment response and overall survival, it is important to analyze which variables impact these relationships. The results showed the importance of psychological variables such as distress, body image, and family stress on QoL. With increased survival rates and life-expectancy, it becomes paramount to assess women on such variables in order to improve their wellbeing and decrease their negative impact on QoL.

The present study focused on the relationship between clinical and psychological variables in breast cancer showing the role of family stress in the relationship between psychological distress and QoL. According to the results, it is important to screen and intervene on family stress in patients with breast cancer. We believe that, in cases where the screening reveals high family stress, the intervention should be offered in a family context. The family is an essential context of disease management and source of support and family support from partners was found to be the most important support by breast cancer women, acting as a buffer against psychological distress (Hasson-Ohayon, Goldzweig, Braun, \& Galinsky, 2010).

The main limitations of this study were the cross sectional design, the exclusive use of self-report measures, and the use of the EORTC QLQ-C30 questionnaire to assess QoL, while the specific measure of EORTC QLQ-BR23 would have been more adequate in breast cancer. Also, the type of chemotherapy protocol was not taken into consideration. Future studies should follow breast cancer women using longitudinal designs in order to identify patterns of adaptation to cancer and QoL, during the different stages of treatment with different chemotherapy treatment protocols and assess the role of family stress on patients' QoL, as the duration of diagnosis increases.

bidity? European Journal of Surgical Oncology (EJSO), 25(6), 571-573. doi:10.1053/ejso.1999.0708

Allison, P., Guichard, C., \& Gilain, L. (2000). A prospective investigation of dispositional optimism as a predictor of health-related quality of life in head and neck cancer patients. Quality of Life Research, 9(8), 951-960. doi:10.1023/A:1008931906253 
Applebaum, A., Stein, E., Lord-Bessen, J., Pessin, H., Rosenfeld, B., \& Breitbart, W. (2013). Optimism, social support, and mental health outcomes in patients with advanced cancer. Psycho-Oncology, 23(3), 299-306. doi: $10.1002 /$ pon. 3418

Ardebil, M., Bouzari, Z., Shenas, M., Zeinalzadeh, M., \& Barat, S. (2011). Depression and health related quality of life in breast cancer patients. Academic Journal of Cancer Research, 4(2), 43-46.

Avis, N., Crawford, S., \& Manuel, J. (2005). Quality of life among younger women with breast cancer. Journal of Clinical Oncology, 23(15), 33223330. doi:10.1200/jco.2005.05.130

Badger, T., Braden, C., Mishel, M., \& Longman, A. (2004). Depression burden, psychological adjustment, and quality of life in women with breast cancer: Patterns over time. Research in Nursing \& Health, 27(1), 19-28. doi:10.1002/nur.20002

Baron, R., \& Kenny, D. (1986). The moderator-mediator variable distinction in social psychological research: Conceptual, strategic, and statistical considerations. Journal of Personality and Social Psychology, 51(6), 11731182. doi:10.1037//0022-3514.51.6.1173

Braun, D., Gupta, D., Grutsch, J., \& Staren, E. (2011). Can changes in health related quality of life scores predict survival in stages III and IV colorectal cancer? Health and Quality of Life Outcomes, 9(1), 62. doi:10.1186/1477-7525-9-62

Breast Cancer Treatment Option Overview. (2018, August 22). National Cancer Institute [Webpage]. Retrieved from http://www.cancer.gov/cancertopics/pdq/treatment/breast/Patient/ page $5 \#$ Keypoint 23

Browall, M., Ahlberg, K., Karlsson, P., Danielson, E., Persson, L., \& Gaston-Johansson, F. (2008). Health-related quality of life during adjuvant treatment for breast cancer among postmenopausal women. European Journal of Oncology Nursing, 12(3), 180-189. doi:10.1016/j.ejon.2008.01.005

Carver, C. S., Scheier, M. F., \& Segerstrom, S. C. (2010). Optimism. Clinical Psychology Review, 30, 879-889. doi:10.1016/j.cpr.2010.01.006

Carver, C., Smith, R., Antoni, M., Petronis, V., Weiss, S., \& Derhagopian, R. (2005). Optimistic personality and psychosocial well-being during treatment predict psychosocial well-being among long-term survivors of breast cancer. Health Psychology, 24(5), 508-516. doi:10.1037/02786133.24.5.508

Carver, C., Smith, R., Petronis, V., \& Antoni, M. (2006). Quality of life among long-term survivors of breast cancer: Different types of antecedents predict different classes of outcomes. Psycho-Oncology, 15(9), 749-758. doi:10.1002/pon.1006

Colby, D., \& Shifren, K. (2013). Optimism, mental health, and quality of life: A study among breast cancer patients. Psychology, Health \& Medicine, 18(1), 10-20. doi:10.1080/13548506.2012.686619

Collins, K., Liu, Y., Schootman, M., Aft, R., Yan, Y., Dean, G, ... Jeffe, D. (2010). Effects of breast cancer surgery and surgical side effects on body image over time. Breast Cancer Research and Treatment, 126(1), $167-$ 176. doi:10.1007/s10549-010-1077-7

Edwards, B., \& Clarke, V. (2004). The psychological impact of a cancer diagnosis on families: The influence of family functioning and patients' illness characteristics on depression and anxiety. Psycho-Oncology, 13(8), 562-576. doi: $10.1002 /$ pon. 773

Ferlay, J., Steliarova-Foucher, E., Lortet-Tieulent, J., Rosso, S., Coebergh, J., Comber, H., ... Bray, F. (2013). Cancer incidence and mortality patterns in Europe: Estimates for 40 countries in 2012. European Journal of Cancer, 49(6), 1374-1403. doi:10.1016/j.ejca.2012.12.027

Fobair, P., Stewart, S., Chang, S., D'Onofrio, C., Banks, P., \& Bloom, J. (2006). Body image and sexual problems in young women with breast cancer. Psycho-Oncology, 15(7), 579-594. doi:10.1002/pon.991

Gupta, D., Granick, J., Grutsch, J., \& Lis, C. (2006). The prognostic association of health-related quality of life scores with survival in breast cancer. Supportive Care in Cancer, 15(4), 387-393. doi:10.1007/s00520-0060165-z

Härtl, K., Engel, J., Herschbach, P., Reinecker, H., Sommer, H., \& Friese, K. (2010). Personality traits and psychosocial stress: Quality of life over 2 years following breast cancer diagnosis and psychological impact factors. Psycho-Oncology, 19(2), 160-169. doi:10.1002/pon.1536
Hasson-Ohayon, I., Goldzweig, G., Braun, M., \& Galinsky, D. (2010). Women with advanced breast cancer and their spouses: diversity of support and psychological distress. Psycho-Oncology, 19, 1195-1204. doi:10.1002/pon.1678

Helms, R., O'Hea, E., \& Corso, M. (2008). Body image issues in women with breast cancer. Psychology, Health \& Medicine, 13(3), 313-325. doi: $10.1080 / 13548500701405509$

Ho, S., So, W., Leung, D., Lai, E., \& Chan, C. (2013). Anxiety, depression and quality of life in Chinese women with breast cancer during and after treatment: A comparative evaluation. European Journal of Oncology Nursing, 17(6), 877-882. doi:10.1016/j.ejon.2013.04.005

Holzner, B., Kemmler, G., Kopp, M., Moschen, R., Schweigkofler, H., Dunser, M., ... Sperner-Unterweger, B. (2001). Quality of life in breast cancer patients - not enough attention for long-term survivors? Psychosomatics, 42(2), 117-123. doi:10.1176/appi.psy.42.2.117

Hopwood, P., Fletcher, I., Lee, A., \& Al-Ghazal, S. (2001). A body image scale for use with cancer patients. European Journal of Cancer, 37(2), 189197. doi:10.1016/s0959-8049(00)00353-1

Hudson, W. (1992). The Walmyr Assessment Scales Scoring Manual. Tempe: Walmyr Publishing Company.

Kissane, D., Bloch, S., Dowe, D., Snyder, R., Onghena, P., McKenzie, D., \& Wallace, C. (1996). The Melbourne Family Grief Study, I: Perceptions of family functioning in bereavement. American Journal of Psychiatry, 153(5), 650-658. doi:10.1176/ajp.153.5.650

Laranjeira, C. (2008). Tradução e validação portuguesa do Revised Life Orientation Test (LOT-R) [Portuguese translation and validation of the Revised Life Orientation Test (LOT-R)]. Universitas Psychologica, 7(2), 469-476.

Lemieux, J., Maunsell, E., \& Provencher, L. (2008). Chemotherapy-induced alopecia and effects on quality of life among women with breast cancer: A literature review. Psycho-Oncology, 17(4), 317-328. doi: $10.1002 /$ pon. 1245

Leung, J., Atherton, I., Kyle, R., Hubbard, G., \& McLaughlin, D. (2015). Psychological distress, optimism and general health in breast cancer survivors: A data linkage study using the Scottish Health Survey. Supportive Care in Cancer, 24(4), 1755-1761. doi:10.1007/s00520-015-2968-2

Livneh, H., \& Antonak, R. (2005). Psychosocial adaptation to chronic illness and disability: A primer for counselors. Journal of Counseling \& Development, 83(1), 12-20. doi:10.1002/j.1556-6678.2005.tb00575.x

Montazeri, A. (2008). Health-related quality of life in breast cancer patients: A bibliographic review of the literature from 1974 to 2007. Journal of Experimental \& Clinical Cancer Research, 27(1), 32. doi:10.1186/17569966-27-32

Moreira, C. B., Fernandes, A. F., Gomes, A. M., Silva A. M., \& Santos, M. C. (2013). Educational strategy experimented with mastectomized women: Experience report. Revista de Enfermagem UFPE On Line, 7(1), 302-305. doi:10.5205/r euol.3049-24704-1-LE.0701201339

Moreira, H., Silva, S., Marques, A., \& Canavarro, M. (2010). The Portuguese version of the Body Image Scale (BIS) - psychometric properties in a sample of breast cancer patients. European Journal of Oncology Nursing, 14(2), 111-118. doi:10.1016/j.ejon.2009.09.007

Northouse, L., Kershaw, T., Mood, D., \& Schafenacker, A. (2005). Effects of a family intervention on the quality of life of women with recurrent breast cancer and their family caregivers. Psycho-Oncology, 14(6), 478-491. doi:10.1002/pon.871

Northouse, L., Mood, D., Kershaw, T., Schafenacker, A., Mellon, S., Walker, J., ... Decker, V. (2002). Quality of life of women with recurrent breast cancer and their family members. Journal of Clinical Oncology, 20(19), 4050-4064. doi:10.1200/jco.2002.02.054

Ogden, J. (2004). Understanding Breast Cancer. Lisbon: Climepsi Editores.

Pais-Ribeiro, J., Silva, I., Ferreira, T., Martins, A., Meneses, R., \& Baltar, M. (2007). Validation study of a Portuguese version of the Hospital Anxiety and Depression Scale. Psychology, Health and Medicine, 12, 225-237. doi: $10.1080 / 13548500500524088$

Pais-Ribeiro, J., Pinto, C., \& Santos, C. (2008). Validation study of the Portuguese version of the QLC-C30-V.3. Psicologia, Saúde \& Doenças, 9(1), 89-102.

Penttinen, H., Saarto, T., Kellokumpu-Lehtinen, P., Blomqvist, C., Huovinen, R., Kautiainen, H., ... Hakamies-Blomqvist, L. (2010). 
Quality of life and physical performance and activity of breast cancer patients after adjuvant treatments. Psycho-Oncology, 20(11), 1211-1220. doi:10.1002/pon.1837

Pereira, M., \& Roncon, J. (2010). Relacionamento familiar em pessoas idosas: Adaptação do Índice de Relações Familiares (IFR) [Family relations in the elderly: Adaptation of the Index of Family Relations (IFR)]. Psicologia, Saúde \& Doencas, 11(1), 41-53.

Petersen, L., Clark, M., Novotny, P., Kung, S., Sloan, J., Patten, C., ... Colligan, R. (2008). Relationship of optimism-pessimism and healthrelated quality of life in breast cancer survivors. Journal of Psychosocial Oncology, 26(4), 15-32. doi:10.1080/07347330802359578

Rabin, E., Heldt, E., Hirakata, V., \& Fleck, M. (2008). Quality of life predictors in breast cancer women. European Journal of Oncology Nursing, 12(1), 53-57. doi:10.1016/j.ejon.2007.06.003

Rasmussen, H., Scheier, M., \& Greenhouse, J. (2009). Optimism and physical health: A meta-analytic review. Annals of Behavioral Medicine, 37(3), 239-256. doi:10.1007/s12160-009-9111-x

Reece, J., Chan, Y., Herbert, J., Gralow, J., \& Fann, J. (2013). Course of depression, mental health service utilization and treatment preferences in women receiving chemotherapy for breast cancer. General Hospital Psychiatry, 35(4), 376-381. doi:10.1016/j.genhosppsych.2013.03.017

Reich, M., Lesur, A., \& Perdrizet-Chevallier, C. (2007). Depression, quality of life and breast cancer: A review of the literature. Breast Cancer Research and Treatment, 110(1), 9-17. doi:10.1007/s10549-007-9706-5

Rosenberg, S., Tamimi, R., Gelber, S., Ruddy, K., Kereakoglow, S., Borges, V., ... Partridge, A. (2012). Body image in recently diagnosed young women with early breast cancer. Psycho-Oncology, 22(8), 1849-1855. doi:10.1002/pon.3221

Scheier, M., \& Carver, C. (1985). Optimism, coping ad health: Assessment and implications of generalized outcome expectancies. Health Psychology, 4(3), 219-247. doi:10.1037/0278-6133.4.3.219

Scheier, M., \& Carver, C. (1992). Effects of optimism on psychological and physical well-being: Theoretical overview and empirical update. Cognitive Therapy and Research, 16(2), 201-228. doi:10.1007/bf01173489

Scheier, M., Carver, C., \& Bridges, M. (1994). Distinguishing optimism from neuroticism (and trait anxiety, self-mastery, and self-esteem): A reevaluation of the Life Orientation Test. Journal of Personality and Social Psychology, 67(6), 1063-1078. doi:10.1037/0022-3514.67.6.1063

Schou, I., Ekeberg, Ø., Sandvik, L., Hjermstad, M., \& Ruland, C. (2005). Multiple predictors of health-related quality of life in early stage breast cancer. Data from a year follow-up study compared with the general population. Quality of Life Research, 14(8), 1813-1823. doi:10.1007/s11136-005-4344-z

Seidl, E., \& Zannon, C. (2004). Qualidade de vida e saúde: Aspectos conceituais e metodológicos [Quality of life and health: Conceptual and methodological issues]. Cadernos de Saúde Pública, 20(2), 580-588. doi:10.1590/s0102-311x2004000200027

Seligman, M. (1992). Learned optimism: How to change your mind and your life. New York: Pocket Books.

Shifren, K. (1996). Individual differences in the perception of optimism and disease severity: A study among individuals with Parkinson Disease. Journal of Behavioral Medicine, 19(3), 241-271. doi:10.1007/BF01857768

Shifren, K., \& Hooker, K. (1995). Stability and change in optimism: A study among spouse caregivers. Experimental Aging Research, 21(1), 59-76. doi:10.1080/03610739508254268

Silva, S., Bettencourt, D., Moreira, H., \& Canavarro, M. C. (2011). Qualidade de vida de mulheres com cancro da mama nas diversas fases da doença: $\mathrm{O}$ papel de variáveis sociodemográficas, clínicas e das estratégias de coping enquanto fatores de risco/proteção [Quality of life of women with breast cancer at different phases of the disease: The role of sociodemographic, clinical variables and coping strategies as factors of risk/protection]. Revista Portuguesa de Saúde Pública, 29(1), 64-76. doi:10.1016/S0870-9025(11)70009-8

So, W., Marsh, G., Ling, W., Leung, F., Lo, J., Yeung, M., \& Li, G. (2010). Anxiety, depression and quality of life among Chinese breast cancer patients during adjuvant therapy. European Journal of Oncology Nursing, 14(1), 17-22. doi:10.1016/j.ejon.2009.07.005

Stanton, A., Revenson, T., \& Tennen, H. (2007). Health psychology: Psychological adjustment to chronic disease. Annual Review of Psychology, 58(1), 565-592. doi:10.1146/annurev.psych.58.110405.085615

Thomas, C., Morris, S., \& Harman, J. (2002). Companions through cancer: The care given by informal carers in cancer contexts. Social Science 2 Medicine, 54(4), 529-544. doi:10.1016/s0277-9536(01)00048-x

Vilhena, E., Pais-Ribeiro, J., Silva, I., Pedro, L., Meneses, R., Cardoso, H., ... Mendonça, D. (2014). Optimism on quality of life in Portuguese chronic patients: Moderator/mediator? Revista da Associação Médica Brasileira, 60(4), 373-380. doi:10.1590/1806-9282.60.04.017

White, C. (2000). Body image dimensions and cancer: A heuristic cognitive behavioural model. Psycho-Oncology, 9(3), 183-192. doi:10.1002/10991611(200005/06)9:3<183::aid-pon446>3.0.co;2-1

White, C. A., \& Hood, C. (2011). Body image issues in oncology. In T. F. Cash \& L. Smolak (Eds.), Body image: A handbook of science, practice and prevention (pp. 333-341). Guilford Press.

Zenger, M., Brix, C., Borowski, J., Stolzenburg, J., \& Hinz, A. (2009). The impact of optimism on anxiety, depression and quality of life in urogenital cancer patients. Psycho-Oncology, 19(8), 879-886. doi: $10.1002 /$ pon. 1635

Zigmond, A., \& Snaith, R. (1983). The Hospital Anxiety and Depression Scale. Acta Psychiatrica Scandinavica, 67(6), 361-370. doi:10.1111/j.16000447.1983.tb09716.x 